\title{
Commentary Clostridium difficile: the increasingly difficult pathogen
} Aurora Pop-Vicas and Marguerite A Neill

\begin{abstract}
Warren Alpert Medical School, Brown University, Division of Infectious Diseases, Memorial Hospital of Rhode Island, 111 Brewster Street, Pawtucket, RI 02860, USA
\end{abstract}

Corresponding author: Aurora Pop-Vicas, Aurora_Pop-Vicas@brown.edu

Published: 7 February 2008

This article is online at http://ccforum.com/content/12/1/114

(c) 2008 BioMed Central Ltd

Critical Care 2008, 12:114 (doi:10.1186/cc6773)

See related review by Gould and McDonald, http://ccforum.com/content/12/1/203

\begin{abstract}
The epidemiology of Clostridium difficile infection is changing as a result of the epidemic spread of the hypervirulent North American Pulsefield type 1 strain. Clinicians are likely to encounter this disease more frequently than ever in their practice, and should be familiar with the updates in its diagnosis and treatment.
\end{abstract}

In the present issue of Critical Care, Gould and McDonald [1] provide a comprehensive, up-to-date review of Clostridium difficile - a pathogen of increasing concern worldwide. Recognized as the main cause of antibiotic-associated diarrhea for several decades [2], Clostridium difficile infection (CDI) had developed a reputation more as an economic challenge than a therapeutic one. That perception has changed dramatically in recent years, after several outbreaks of unprecedented severity, with increased frequency of complications such as septic shock, toxic megacolon, colectomy, and death were reported in the United States and Canada $[3,4]$. This different clinical picture is attributed to the emergence of a new C. difficile strain, designated North American Pulsefield type 1 (NAP1). This strain's heightened virulence correlates with 20-fold greater toxin production compared with historical strains $[1,2]$. Intriguingly, the NAP1 strain has been found in cattle and other animals, as well as in retail ground meat [5], but food-borne transmission has not been proven.

In light of the changing epidemiology and spectrum of C. difficile disease, what are the implications for clinicians?

\section{Need for early diagnosis, with increased index of suspicion in nontraditional populations}

The majority of CDI still occurs in patients with wellrecognized risk factors - antibiotic exposure and advanced age, hospitalization, or nursing-home residence. CDI has also been reported, however, in patients previously considered at low risk for the disease, such as healthy patients from the community [6], postpartum women, and perhaps patients on gastric acid suppressive medications [7]. The toxin enzyme immunoassay remains the main diagnostic modality in most clinical settings [6] but is rather insensitive, necessitating the submission of at least two specimens to improve the diagnostic yield. Prompt initiation of effective therapy can be crucial, especially in light of the rapid progression to fulminant disease observed with the NAP1 strain. Empiric treatment is now recommended immediately after specimen collection for patients with severe CDI $[8,9]$, and the disease should be suspected in patients with unexplained leukemoid reaction even in the absence of diarrhea [10].

\section{Changing treatment concepts}

Metronidazole has been historically recommended as first-line CDI therapy primarily due to its low cost, its noninferiority to vancomycin, and its lower propensity for colonization with vancomycin-resistant enterocci and staphylococci [8]. Metronidazole remains a viable option for mild to moderate disease [1,9]. Recent data from observational studies and clinical experience suggest that metronidazole's efficacy may be decreasing [11], and a switch to oral vancomycin is indicated if at least some symptomatic improvement is not observed after 1-2 days of metronidazole treatment [9]. Oral vancomycin remains the preferred treatment for severe disease - defined in a recent randomized controlled trial [12] as the presence of pseudomembranous colitis or intensive care unit hospitalization, or the presence of two or more of the following: age $>60$ years, temperature $>38.3^{\circ} \mathrm{C}$, white blood cell count $>15,000 \mathrm{cells} / \mathrm{mm},{ }^{3}$ albumin $<2.5 \mathrm{mg} / \mathrm{dl}$. As emphasized by Gould and McDonald in their review article [1], efforts must be directed to ensure drug delivery to the lumen of the colon in patients with decreased peristalsis and ileus [9]. 


\section{Early surgical consultation}

Previously CDI was rarely a surgical disease, but recent experience is demonstrating otherwise. Emergency colectomy has been noted to improve survival in severely ill patients [13]. The clinical challenge is in identifying the patients warranting colectomy and its timing. In patients with suspected severe CDI, and those with ileus or toxic megacolon, an early surgical consultation should be obtained $[9,13]$.

\section{Continuing challenges}

Perhaps the most frustrating aspect of CDI for the patient and physician is the high relapse rate $(25 \%)$, and, in some patients, the multiple recurrences after discontinuation of $C$. difficile therapy [2]. This aspect of management is particularly difficult since there are no formal treatment guidelines, and the therapeutic options currently used - such as vancomycin with long tapers or pulsed doses, fecal implants, use of probiotics, or intravenous immunoglobulin - are based on anecdotal evidence from case reports or case series $[2,9]$.

A variety of new therapeutic agents are currently under investigation, and they are nicely summarized in the article by Gould and McDonald [1].The research into defining the role played by the host's immune responses in determining disease outcome is particularly exciting [14], and immunomodulatory therapies with monoclonal antibodies and a $C$. difficile vaccine are currently undergoing phase 2 clinical trials [15].

Until better treatment options, with agents that remediate disease more quickly and with fewer relapses, become available, the responsibility for interrupting nosocomial C. difficile transmission remains literally 'in our hands,' through the proper use of hand hygiene, through consistent and early isolation of infected patients, through antibiotic stewardship, and thorough environmental cleaning.

\section{Competing interests}

The authors declare that they have no competing interests.

\section{References}

1. Gould C, McDonald C: Bench-to-bedside review: Clostridium difficile colitis. Crit Care 2008, 12:203.

2. Bartlett JG: New drugs for Clostridium difficile infection. Clin Infect Dis 2006, 43:428-431.

3. Pepin J, Valiquette L, Alary ME, Villemure P, Pelletier A, Forget K, Pepin K, Chouinard D: Clostridium difficile-associated diarrhea in a region of Quebec from 1991 to 2003: a changing pattern of disease severity. CMAJ 2004, 171:466-472.

4. McDonald LC, Killgore GE, Thompson A, Owens RC Jr, Kazakova SV, Sambol SP, Johnson S, Gerding DN: An epidemic, toxin gene-variant strain of Clostridium difficile. N Engl J Med 2005, 353:2433-2441.

5. Rupnik M: Is Clostridium difficile-associated infection a potentially zoonotic and foodborne disease? Clin Microbiol Infect 2007, 13:457-459.

6. Blossom DB, McDonald C: The challenges posed by reemerging Clostridium difficile infection. Clin Infect Dis 2007, 45:222227.
7. Dial S, Delaney Ja, Barkun An, Suissa S: Use of gastric acidsuppressive agents and the risk of community-acquired Clostridium difficile-associated disease. JAMA 2005, 294: 2989-2995.

8. Bartlett J: Historical perspectives on studies of Clostridium difficile and C. difficile infection. Clin Infect Dis 2008, 46:S4-S11.

9. Gerding D, Muto C, Owens R: Treatment of Clostridium difficile infection. Clin Infect Dis 2008, 46:S32-S42.

10. Wanahita A, Goldsmith EA, Marino BJ, Musher DM: Clostridium difficile infection in patients with unexplained leukocytosis. Am J Med 2003, 115:543-546.

11. Musher DM, Aslam S, Logan N, Nallacheru S, Bhaila I, Borchert F, Hamill RJ: Relatively poor outcome after treatment of Clostridium difficile colitis with metronidazole. Clin Infect Dis 2005, 40:1586-1590.

12. Zar FA, Bakkanagari SR, Morrthi KM, Davis MB: A comparison of vancomycin and metronidazole for the treatment of Clostridium-difficile-associated diarrhea, stratified by disease severity. Clin Infect Dis 2007, 45:302-307.

13. Lamontagne $F$, Labbe $A C$, Haeck $O$, Lesur $O$, Lalancette $M$, Putino C, Leblanc M, Laverdiere M, Pepin J: Impact of emergency colectomy on survival of patients with fulminant Clostridium difficile colitis during an epidemic caused by a hypervirulent strain. Ann Surg 2007, 254:267-272.

14. Kyne L, Warny M, Qamar A, Kelly CP: Association between antibody response to toxin $A$ and protection against recurrent Clostridium difficile diarrhea. Lancet 2001, 357:189-193.

15. Miller, M: Clinical management of Clostridium difficile-associated disease. Clin Infect Dis 2007, 45:S122-S128. 